$\begin{array}{ll}\text { Abstracta Iranica } & \begin{array}{l}\text { Abstracta Iranica } \\ \text { Revue bibliographique pour le domaine irano-aryen }\end{array} \\ & \text { Volume } \mathbf{3 0} \mid \mathbf{2 0 1 0} \\ & \text { Comptes rendus des publications de } \mathbf{2 0 0 7}\end{array}$

\title{
Let Me Tell You Where I've Been: New Writing by Women of the Iranian Diaspora. Fayetteville, The University of Arkansas Press, 2006, 400 p.
}

Laetitia Nanquette (Bif)

\section{(2) OpenEdition \\ Journals}

Édition électronique

URL : http://journals.openedition.org/abstractairanica/38047

DOI : 10.4000/abstractairanica.38047

ISSN : 1961-960X

Éditeur :

CNRS (UMR 7528 Mondes iraniens et indiens), Éditions de l'IFRI

Édition imprimée

Date de publication : 8 avril 2010

ISSN : 0240-8910

Référence électronique

Laetitia Nanquette (Bif), « Let Me Tell You Where I've Been: New Writing by Women of the Iranian Diaspora. Fayetteville, The University of Arkansas Press, 2006, 400 p. », Abstracta Iranica [En ligne], Volume 30 | 2010, document 280, mis en ligne le 08 avril 2010, consulté le 26 septembre 2020. URL : http:// journals.openedition.org/abstractairanica/38047 ; DOI : https://doi.org/10.4000/abstractairanica. 38047

Ce document a été généré automatiquement le 26 septembre 2020.

Tous droits réservés 


\title{
Let Me Tell You Where I've Been: New
} Writing by Women of the Iranian Diaspora. Fayetteville, The University of Arkansas Press, 2006, $400 \mathrm{p}$.

\author{
Laetitia Nanquette (Bif)
}

1 Persis Karim a réuni dans ce recueil des nouvelles, poèmes, essais et extraits de mémoires par une cinquantaine de femmes iraniennes composant en langue anglaise et vivant dans la diaspora, principalement aux États-Unis.

2 Après la révolution de 1979, les femmes ont pris le pas dans la littérature iranienne, aussi bien en Iran qu'au sein de la diaspora. Karim avance comme explication de cette prédominance féminine, outre le changement profond de la tradition littéraire de l'Iran, pendant longtemps principalement le domaine des hommes, la nécessité pour celles qui ont vécu l'expérience de l'exil de redéfinir leur identité. Pour nombre d'entre ces femmes, le meilleur moyen d'exprimer une identité composite se trouve dans l'utilisation de la langue anglaise, et sa combinaison avec une écriture du souvenir.

3 Le recueil est organisé par thèmes. On trouve ainsi dans « Home Stories » des textes qui traitent de l'exil et du foyer, dans « For Tradition », des écrits sur la culture iranienne, ses traditions et l'importance de la famille; "Woman's Duty» renvoie au rôle des femmes dans les deux sociétés entre lesquelles elles se partagent, et à leurs expériences passées et présentes, «Axis of Evil » comprend des textes politiques, traitant aussi bien de la guerre contre l'Irak que de la politique américaine contemporaine, tandis que «Beyond » et «Tales left Untold» parlent d'amour, de nostalgie, de rêves, et élargit l'horizon à des thèmes universels et non plus seulement iraniens.

4 L'objet de ce recueil, outre la publication des écrits des Iraniennes de la diaspora, auteures confirmées ou plus jeunes, est d'offrir à un public occidental un aperçu d'un autre Iran, un Iran féminin, poétique et non plus seulement politique, pluriel. Cette 
volonté exprimée par Karim dans son introduction et son judicieux choix de textes, est aussi celle d'Al Young, le poète qui a préfacé l'ouvrage et appelé de ses vœux un rapprochement irano-américain.

INDEX

Thèmes : 11.1.2. Littérature persane moderne

\section{AUTEURS}

\section{LAETITIA NANQUETTE (BIF)}

Paris 